\title{
Uma república entre dois mundos: Inconfidência Mineira, historiografia e temporalidade
}

\author{
João Pinto Furtado \\ Universidade Federal de Minas Gerais
}

\section{RESUMO}

Este artigo procura contribuir para a crítica de algumas teses correntes sobre a Inconfidência Mineira (1789), notadamente aquelas correlatas à afirmação da existência de um projeto liberal e nacional em torno do qual se articularam os inconfidentes mineiros. Gerado em um contexto de transição entre o Antigo Regime e a Modernidade, em que valores estamentais como honra, posição e precedência chocavam-se com emergentes perspectivas de classe, como riqueza, trabalho e propriedade, o movimento foi expressão de uma série de ambigüidades e contradições próprias do período. Seus protagonistas, ações e projetos podem ser melhor compreendidos se considerados no contexto de grande heterogeneidade social e econômica - das quais o conteúdo político e o sentido do movimento são expressões diretas - do que de forte coesão ideológica em torno de um projeto de nação predefinido.

Palavras-chave: Inconfidência Mineira; historiografia; política.

\section{ABSTRACT}

This study is an attempt to make a new reading and a criticism of some of the researches and evidences about the Inconfidência Mineira (1789). It aims at contributing to the criticism of some current theses on the subject, mainly those that corroborate the existence of a defined national and liberal project to which the inconfidentes adhered. Brewed in a context of transition between the Ancien Regime and the Modern Age in rank values such as honor and precedence clashed with emerging class perspectives such as wealth and property, the movement was the expression of ambiguities and contradictions typical of that period. Its performers, actions and projects can be better understood if considered in the context of social and economic heterogeneity which the movement's political content and meaning directly express instead of the context of a strong ideological cohesiveness around a pre-defined project for a Nation. Keywords: Inconfidência Mineira; historiography; politics. 
Discutindo a construção do objeto de estudo, bem como a metodologia de trabalho do historiador, Lucien Febvre já nos advertia, no início do século XX, para um dos principais cuidados que devem presidir o trabalho da historiografia contemporânea: o historiador de ofício precisa sempre evitar o maior dos pecados, o anacronismo, terrível deslize metodológico que reduz duas épocas distintas a uma mesma significação. 0 pressuposto da afirmativa é o de que acontecimentos históricos pontuais só se tornam inteligíveis a partir do conhecimento mais amplo de todo o complexo histórico que os engendrou, tanto no que respeita a seus aspectos mais propriamente objetivos, quanto até mesmo no que respeita à sintaxe e semântica dos termos empregados. A esta opção metodológica está visceralmente ligada a noção de "aparelhagem mental", uma conceituação que preceitua identificar e analisar os instrumentos disponíveis numa dada sociedade, para formulação das representações e problemas da mesma. Portanto, explícita é a formulação de que estabelecer uma relação com o passado é estabelecer um diálogo entre duas épocas distintas e, nesse sentido, quando vamos trabalhar com as interpretações e conceitos comumente associados à Inconfidência Mineira é preciso não perder de vista o fato de que, embora palavras e elementos de linguagem de diferentes épocas se aproximem e possam ser associados e utilizados como elementos de investigação e demonstração analógica, não podem ser reduzidos à mesma significação.

É preciso, nesse caso, colocar sob suspeição alguns termos que se tornaram cânones no pensamento político contemporâneo mas que, no século XVIII, ainda não possuíam a conotação que hoje lhes damos. É preciso estudar as estruturas lingüísticas, as estruturas de pensamento, o conhecimento disponível e os conceitos, as formas de sensibilidade e percepção dos temas de debate e intervenção. 0 historiador, ávido por "interpretar” e se imiscuir numa época da qual só sobraram alguns fragmentos, deve lançar mão de quaisquer recursos que estejam à sua disposição e, nesse sentido, pensar também nas diferentes leituras que se empreenderam sobre o tema em perspectiva histórica, as quais estão em estreita relação com as práticas sociais mais imediatas que as instituíram. Assim é o caso de que nos ocuparemos, qual seja o das diversas concepções de República que poderiam, no contexto setecentista, estar servindo como parâmetro de referência aos inconfidentes mineiros de 1788-89 e seu tratamento pela historiografia.

Escrevendo sobre as diversas variantes históricas do termo República, o cientista político Nicola Matteucci nos adverte que o sentido geral mais persistente no tempo é derivado da dupla conjunção feita por Cícero (103-46 a.C.) no contexto do século primeiro a.C.. O conhecido orador romano teria esboçado, em De Republica, uma definição de República como forma de governo que se constrói em torno da articulação conseqüente das idéias de "utilidade comum" 
(utilitatis communione sociatus) e "consenso jurídico" (iuris consensu). Tal noção passaria a ser corrente, ou serviria de parâmetro, praticamente até a Revolução Francesa ${ }^{1}$. Ainda segundo Matteucci, ao construir assim seu argumento, Cícero promove uma sensível cesura em relação aos termos segundo os quais era tratada a questão entre os gregos. Se os últimos referiam o termo através da contraposição entre Monarquia e República, governo de um só ou governo de vários, os romanos, a partir de Cícero, passam a fazer outra clivagem, mais referenciada à dicotomia justiça $\mathrm{x}$ injustiça, expressa na idéia de iuris consensu, 0 que, segundo nosso autor, serviria como parâmetro praticamente até Kant, inclusive. A expectativa por um governo da Res Publicae tornar-se-ia, por assim dizer, a reafirmação da expectativa de um governo legalmente constituído e que praticasse a justiça, ou seja, que coerentemente articulasse "consenso jurídico" e "utilidade comum". Salvaguardados estes princípios, o tema conheceu na modernidade pequenas variações. Jean Bodin (1530-96) enfatiza em seus textos a questão da soberania do governante, desde que em contexto de droit governement, e por isto admite o uso do termo República também para que faça referência às monarquias, desde que supram o princípio do governo justo.

John Locke (1632-1704), por seu turno, no apagar das luzes seiscentistas, afirma e realça, sobretudo nos "Dois tratados sobre o governo" (1690), a questão da origem popular de toda forma de autoridade. Ainda não definia claramente, no entanto, como fariam seus admiradores e sucessores, os founding fathers norte-americanos John Adams e Alexander Hamilton, a questão do sistema representativo, do voto, e portanto, da soberania popular em sentido mais contemporâneo. Consentimento (expresso e tácito) seriam os fundamentos, em Locke, da permanência do governante no cargo, desde que este afirmasse o primado da lei e assegurasse a liberdade individual e religiosa. Suas idéias foram a base teórica da qual beberam alguns dos americanos da porção setentrional para constituir os contornos iniciais do novo Estado americano ${ }^{2}$.

Em Montesquieu (1689-1755), autor que para nós é objeto de redobrada atenção, o tratamento da questão também se sofistica. 0 principal título deste autor, L'espirit des Lois (1745), foi citado no seqüestro dos bens do cônego Vieira, inconfidente de reconhecida erudição e propalada ascendência intelectual sobre os demais sediciosos mineiros. Pode ter sido, junto ao texto do Recueil des loix constitutives des colonies angloises, e ao livro do abade Raynal, bem como outras obras lapidares do Iluminismo, importante referência na gênese do conteúdo do movimento, sobretudo no que respeita à organização política ${ }^{3}$. Dentre os diversos autores arrolados nos seqüestros de livrarias dos inconfidentes, é o que mais representatividade poderia ter, do ponto de vista de uma teoria política, tendo sido consagrado pela ciência política contemporânea como um clássico do século XVIII ${ }^{4}$. 
No "Espírito das Leis" (1745) o pensador francês advoga, ainda em nome da aspiração a um governo justo, a separação de poderes, base da maior parte das constituições liberais que se disseminariam a partir do século XIX. Por outro lado, no que tange à construção do conceito de República no século XVIII, é conveniente reproduzir um trecho em que são resumidas pelo cientista político Nicola Matteucci algumas características pertinentes à abordagem que aqui será realizada. Montesquieu constrói sua tipologia das Repúblicas a partir de quatro pontos centrais:

0 primeiro é o espaço: a República deve ter uma expressão territorial assaz modesta, há que ser pequena enquanto a Monarquia precisa de um espaço grande e 0 despotismo de um espaço ainda maior. Em segundo lugar, na República tem que haver uma relativa igualdade, na monarquia desigualdade em benefício de uma nobreza que é necessária para a própria existência do poder real, no despotismo aquela igualdade que se dá quando todos são escravos. Em terceiro lugar, na República, as leis são expressão da vontade popular, enquanto na Monarquia são expressão da vontade do rei, limitado contudo pelas leis fundamentais (ele é obrigado a governar segundo leis fixas e estáveis, que são aplicadas por um poder judiciário independente) e o déspota governa por decretos ocasionais e improvisados. Em quarto lugar, são diferentes as forças de integração social: na República é a virtude que leva os cidadãos a antepor o bem do Estado ao interesse particular; na monarquia é o senso de honra, da nobreza que é sustentáculo, e ao mesmo tempo limite do poder do rei; no despotismo é o medo que paralisa os súditos. ${ }^{5}$

Logo em seguida, conclui o cientista político, aludindo aos modelos que teriam inspirado Montesquieu, e agora, incluído em sua análise, Rousseau, que diga-se de passagem, não constava em nenhuma das relações de livros apreendidos aos inconfidentes mineiros de 1789:

Na cultura do século XVIII, o mito da República está, desse modo, estreitamente ligado à exaltação do pequeno Estado, o único que consente a Democracia direta, reconhecida como a única forma legítima de democracia. 0 modelo em que se inspirou Rousseau em seu Contrato Social é precisamente Genebra, um modelo novo em confronto com as demais Repúblicas até então idealizadas de Atenas a Roma, de Florença a Veneza. ${ }^{6}$

Só conseguiriam se libertar desta estreita associação entre democracia direta e pequena República, algumas décadas mais tarde, os norte-americanos que, sob a liderança política e intelectual de Adams e Hamilton, re-equacionaram as possíveis dimensões da República através da criação de uma democracia representativa, na qual, através de "sistema de pesos e contrapesos", poder- 
se-iam harmonizar os vários órgãos, poderes e unidades federadas do Estado. Lançavam-se nesse processo as bases e os delineamentos gerais daquilo que, não antes de meados do século XIX, se tornaria a assim chamada República liberal democrática americana, à qual Márcio Jardim e Lúcio dos Santos, autores de referência quanto ao movimento de que nos ocupamos, parecem procurar associar os eventos mineiros de $1789^{7}$.

Malgrado as inúmeras diferenças, intelectuais e cronológicas que separam os diversos autores e correntes citados, procuramos introduzir aqui uma exposição breve e panorâmica exatamente para destacar que há uma longa tradição de debates no que tange à construção dos conceitos de república, sistema representativo e democracia. Nessa longa trajetória, os inconfidentes de Minas estariam situados, precisamente, num momento de redefinição. Tiveram acesso, segundo pode ser documentado pelos "Autos de Seqüestro da Inconfidência Mineira" e pelos depoimentos registrados nos "Autos de Devassa da Inconfidência Mineira", aos textos de Montesquieu, ao Recueil des lois constitutives e ao texto do abade Raynal. Havendo, como há, muitos pontos divergentes entre as várias concepções evocadas por cada um, precisamos tentar identificar, a partir de análise de alguns dos fragmentos do discurso inconfidente, como poderiam ter sido apropriados nas Minas setecentistas.

Os inconfidentes de Minas não pareciam ter ido muito além da proposta de constituição de uma República que ficasse circunscrita a um exíguo padrão espacial. Igualmente parecem não ter avançado muito no que concerne à criação de um sistema de governo que fosse um pouco mais participativo e aberto nos termos de uma democracia direta. Mesmo na Europa e na América do Norte, potências geradoras de muitas destas influências e leituras, apenas se insinuava o acréscimo, à dupla articulação de Cícero (consenso iuris e communione utilitatis), de uma terceira variável, que depois disso seria o grande tema da modernidade: a questão da soberania popular. Consideradas todas essas variáveis e limites, não julgamos ser possível afirmar que, com alguma coerência, os princípios constitutivos de uma democracia participativa e da soberania popular pudessem ser minimamente associados ao contexto setecentista mineiro em geral e a nossos protagonistas em particular. Gostaríamos, portanto, de iniciar nosso exame da questão conferindo especial atenção a alguns dos pontos destacados a partir de Montesquieu, procurando relacioná-los às interpretações correntes na historiografia e ao testemunho dos inconfidentes, expressos em alguns dos fragmentos que se tornaram conhecidos.

No que se refere ao primeiro problema, levantado a partir do que escreve Montesquieu no Espírito das Leis, o do espaço da República, sua abrangência geográfica, de fato, nossas investigações revelaram a necessidade de redimensionar, com expressiva redução da abrangência, o alcance do projeto tal como 
descrito pela historiografia de referência. Segundo Joaquim Norberto Souza e Silva, autor do século XIX, a República projetada pelos inconfidentes "(...) quando muito, estender-se-ia ao Rio de Janeiro e a São Paulo, deixando o resto da colônia entregue ao cativeiro"». Kenneth Maxwell, por seu turno, afirma que os inconfidentes "se inspiravam no exemplo da América do Norte, e nas constituições dos estados da união americana" ", o que nos faz supor que os inconfidentes poderiam estar tratando de uma confederação de Estados independentes a ser estabelecida a partir da ruptura de alguns deles com a metrópole. Já Márcio Jardim afirma textualmente:

(...) tinham em vista a Independência Global do Brasil, não tendo jamais passado por seus planos a hipótese de formar uma república somente em Minas Gerais. A documentação existente permite afirmar que o plano era iniciar a revolta por Minas, estendê-la ao Rio de Janeiro (garantindo a vital saída para o mar) e em seguida às demais capitanias. ${ }^{10}$

Logo adiante, o mesmo autor afirma ainda:

A república seria unitária, mas dividida em províncias, Departamentos ou Regiões Administrativas. É o que se pode depreender da afirmação de que haveria um parlamento principal e outros em diversos locais. No depoimento de José de Resende Costa Filho, apareceu o número de sete parlamentos. Parlamento, logicamente, significava organismo semelhante às nossas atuais Assembléias Legislativas. ${ }^{11}$

Em que pese o reconhecimento do domínio das fontes, manifesto em várias oportunidades por nosso último autor, devemos fazer o reparo sobre sua interpretação, plena de anacronismos. "Logicamente", os inconfidentes tenderiam a referir-se antes aos parâmetros que eram deles conhecidos do que dos que viriam a ser ainda criados ao longo do século XIX. Tendo em vista os problemas levantados e a tentativa de inserção do conceito de república em sua temporalidade, diríamos que os "vários parlamentos", nesse caso, seriam tão-somente os sucedâneos das Câmaras Municipais. Como sabemos, no antigo regime português as câmaras eram os órgãos de representação que reuniam sobretudo os "homens bons" de cada comunidade. Embora tivessem sido severamente golpeadas pela centralização política pombalina, não teriam perdido uma de suas maiores prerrogativas: a de, mesmo submetidas aos governadores, possuírem 0 direito de representação direta ao rei. ${ }^{12}$

Não está afastada, portanto, a possibilidade de que mesmo ao aventarem uma nova ordem, os inconfidentes não estivessem atentos à não-desprezível possibilidade de recuperação de um arcabouço institucional que lhes assegurasse algum nível de representação no mundo luso-brasileiro. A República por eles 
aventada, de fato, teria "vários parlamentos", mas segundo indicam as evidências, distribuídos entre a nova capital proposta, São João del Rey, e as principais localidades que polarizavam a economia das Minas Gerais. Provavelmente, os "parlamentos" seriam distribuídos entre os principais pólos regionais, tradicionais e consolidados - Vila do Carmo, depois Cidade Mariana, Vila Rica, Vila Real do Sabará, Vila de São João del Rey, Vila do Príncipe - e, ainda, alguns emergentes. Nessa última categoria, provavelmente, destacar-se-iam o Arraial de Igreja Nova, que foi logo depois elevada à condição de vila (Vila de Barbacena, em 1791), e o da Campanha do Rio Verde (pouco depois, em 1798, Vila da Campanha da Princesa da Beira).

De fato, tal perspectiva é a que parece se depreender do depoimento de José Resende Costa, o mesmo inconfidente citado por Márcio Jardim. Ainda como testemunha, diz o protagonista:

(...) [o padre Toledo] viera a Vila Rica e achara uns poucos conjurados a fazerem um levante e a reduzirem as Minas a uma República, fazendo vários parlamentos, um na dita Vila, um na de São João, e outros mais, ficando a Vila de São João sendo a Capital; e que os vigários haviam de cobrar todos os dízimos e ficarem com as desobrigas de graça; que o comércio da República havia de consistir na permutação dos efeitos, sem que jamais saísse o ouro para fora. ${ }^{13}$

Observe-se que a testemunha também se refere ao "comércio da República" e, ao que parece, aludindo a um fechamento das fronteiras, "sem que jamais saísse o ouro para fora". Seriam esses pequenos excertos possíveis indicadores das propaladas ligações com os comissários de comércio do Rio de Janeiro? Ainda uma vez, é preciso que se dê voz aos protagonistas, nesse caso, Francisco Antônio de Oliveira Lopes. Em seu primeiro depoimento, diz o coronel sobre os "cariocas" e sua relação com o levante que se projetava:

(...) naqueles conventículos, se havia deliberado que tivessem as Minas o brasão de saírem primeiro; e que, feito o levante, deputaria a República [das Minas] enviados ao Rio de Janeiro dizendo que, se queriam que as Minas satisfizessem o que se devia àquela praça, praticassem ali o mesmo. ${ }^{14}$

Anote-se que as ligações financeiras são colocadas em outro plano e, ao que tudo indica, não é exatamente o plano da contigüidade dos mercados ou da existência de interesses partilhados. Pelo contrário, o coronel sugere certo nível de tensão ligado à existência de dívidas consideráveis dos mineiros em relação aos cariocas que, já àquela altura, haviam sido referidos por Tiradentes como "vis, patifes e pusilânimes". A percepção das diferenças entre as várias comarcas às vezes sugere a inexistência de "complementaridade de interesses" entre os pró- 
prios colonos das Minas Gerais. É preciso considerar, na análise da questão, o fato de que, na organização político-administrativa da Capitania de Minas Gerais, a Comarca do Rio das Mortes, a que mais crescia em termos econômicos e demográficos, estaria relativamente sub-representada, em fins do século XVIII, no que se refere ao número de câmaras existentes, em relação a seus contingentes demográficos, ligações comerciais e atividades econômicas ali empreendidas. Provavelmente este também terá sido, ao mesmo tempo, fator de descontentamento e um dos fatores de desagregação do movimento. De fato, localidades como a Campanha do Rio Verde ou como Borda do Campo/ Igreja Nova, são sobejamente referidas nos autos como algumas daquelas em que grassava maior descontentamento. São os locais de procedência e maior inserção econômica de Francisco Antônio de Oliveira Lopes e do padre Toledo, os únicos que insistiram na deflagração do movimento mesmo após a suspensão da derrama. Campanha do Rio Verde era a sede dos negócios de Alvarenga Peixoto que era - embora tivesse recuado dos propósitos após a suspensão da derrama, junto a Toledo quem esposara o fim da escravidão. Além disso, Borda do Campo, um dos locais onde o movimento ganhou maior publicidade, foi palco da exibição de um dos "quartos" do alferes ${ }^{15}$.

350 Por todo o exposto, segundo acreditamos, não seria mera coincidência o fato de que exatamente aqueles focos de maior rebeldia da Comarca do Rio das Mortes tenham sido, logo em seguida à repressão do levante, os primeiros (e únicos) arraiais atendidos no seu antigo desejo de serem alçados à condição de vila $^{16}$. Isto lhes conferia o direito, não desprezível na ordem setecentista, de constituir Câmara e, portanto, passar a possuir melhor representação "dos povos" ou "das gentes", inclusive com eventual acesso direto à metrópole na forma de petições e requerimentos que pudessem ser apresentados à revelia dos governadores. 0 visconde de Barbacena, ao criar e dar seu próprio nome a uma dessas vilas, parece, num certo sentido, depor contra si mesmo e corroborar as suspeitas quanto à sua ingerência indevida no processo da devassa. Em outras palavras, 0 governador parecia demonstrar, a partir da imediata transformação do arraial de Igreja Nova em vila, que conhecia muito bem o alcance político restrito, os limites e algumas das expectativas da sedição projetada. Nessa perspectiva, é interessante notar que, embora tenha "perdido" alguns de seus "homens bons", como José Aires Gomes, os Resende Costa, Francisco Antônio, padre Toledo e Alvarenga Peixoto, entre outros, a Comarca do Rio das Mortes ganhou duas novas câmaras, o que não é pouco, sobretudo se consideramos que, ao longo de todo o período colonial a capitania teve apenas catorze vilas. Nesse sentido, é lícito admitir que, embora o termo República já fosse usado pelos inconfidentes de 178889 no sentido geral de uma forma de governo, seu detalhamento e definição ain- 
da guardam muita relação com as instituições e práticas do Antigo Regime e da tradição ibérica.

Na mesma linha podemos incluir um breve balanço da estratégia militar do levante. A partir da leitura cruzada das informações contidas nos ADIM, podemos inferir que as estratégias que chegaram a ser efetivamente formuladas eram extremamente defensivas. As únicas alusões concretas a homens em armas referem-se a aproximadamente duzentos homens de Alvarenga (os chamados "pés rapados", conforme denúncia de Joaquim Silvério dos Reis) na Campanha do Rio Verde, cem ou cento e cinqüenta de Francisco Antônio de Oliveira Lopes na região de Borda do Campo e São José del Rey (atual Tiradentes), e sessenta ou cem do padre Rolim no Tijuco ${ }^{17}$. Se, por um lado, essas informações sugerem a possibilidade efetiva de enfrentamento militar, uma vez que o número não é desprezível para os padrões militares da época, por outro lado sugerem os próprios limites da ação projetada. Analisando a situação dos contingentes mencionados em relação à geografia da capitania, percebemos que o horizonte máximo era o de se criar um cinturão de proteção em relação ao núcleo minerador: fechar-se-iam as entradas por São Paulo, via Comarca do Rio das Mortes, pelo Rio de Janeiro, através da Estrada Real e Mantiqueira, e pela Bahia, através do Tijuco. Pretender-se-ia talvez, nesse sentido, antes ganhar algum tempo do que, por exemplo, partir para uma ofensiva que incorporasse uma saída para o mar, fundamental para o escoamento do ouro e entrada de produtos estrangeiros ou a expansão do levante para outras capitanias. Diante disso, a estratégia militar também pouco se coadunava com a suposta unidade nacional pretendida pela futura República. Dos pontos de vista político, econômico e administrativo, por conseguinte, pode-se afirmar que os inconfidentes mineiros não trataram, com base nestes depoimentos, do lançamento das bases de um "projeto nacional" que espelhasse nossa territorialidade atual. Nesse sentido, a "suspeição" de Joaquim Norberto, em 1873, teria maior fundamentação empírica do que a "ilação" de Kenneth Maxwell, em 1973, e que a “conclusão” de Márcio Jardim, em 1988.

No que se refere ao segundo ponto destacado em Montesquieu, correlativo à afirmação da idéia de igualdade relativa como pressuposto da República, gostaríamos de citar alguns trechos e conceitos do Recueil des loix constitutives que, lidos a partir de sua recepção nas Minas, demonstram os limites do eventual "igualitarismo" republicano dos inconfidentes de 1789. Esses elementos indicam, também, algumas das dificuldades de estabelecimento de uma nova ordem pretensamente liberal no bojo de uma sociedade escravocrata e de raízes ainda profundamente ibéricas. Comumente descrito como o livro de cabeceira de Tiradentes e José Alvares Maciel, o Recueil des loix constitutives des colonies angloises, confédéerées sous la dénonination d'États Unis de l'Amérique Septen- 
trionale, editado por Claude Ambrose Regnier em 1778, traz interessantes evidências no que diz respeito ao tema que vimos abordando. Editado apenas dois anos após "os sucessos da revolução americana”, o Recueil é, como o nome indica, uma compilação das leis de alguns dos Estados confederados. Coligidas ao calor da hora, as leis ali contidas não são, ainda, o texto constitucional final, que só seria consolidado onze anos mais tarde, e que provavelmente permaneceu desconhecido dos inconfidentes mineiros. Ainda assim, a coleção de leis e o contexto da independência são sempre sobejamente citados pela historiografia de referência como exemplo cabal da influência norte-americana nos acontecimentos de Minas ${ }^{18}$.

0 exemplo dos americanos do norte foi mencionado ad nauseam por várias das testemunhas e protagonistas de 1788-89. Segundo nossas investigações, no entanto, pode-se perceber que o caso dos americanos do norte foi tomado, exclusivamente, por seu exemplar conteúdo de movimento anticolonial bemsucedido. 0 modo de se "fazer uma revolução" (lido a partir dos acontecimentos na América inglesa e de Raynal) poderia ser relativamente popular, mas param por aí as semelhanças entre americanos do sul e do norte. As premissas liberais de concepção e organização do Estado, o aparato legislativo referente à forma de governo e a concepção de sistema representativo ali ensaiadas e expressas no

352 Recueil não parecem ter se constituído sequer em referência de discussão para os inconfidentes de Minas.

Parecerá um truísmo, mas é preciso lembrar que o fato de que um indivíduo possua livros não quer dizer necessariamente que os leia ou, os lendo, concorde com seu conteúdo. Nesse caso, portanto, existem duas possibilidades: ou o Recueil não foi lido, ou foi lido e objeto de discordância substantiva. Ambas sinalizam para o fato de que, no que se refere às discussões da organização da futura República, a influência dos norte-americanos foi pífia, tendo os inconfidentes de Minas, ao que parece, preferido adotar alguns dos princípios esposados por Montesquieu, a partir do que se esboçaria um outro modelo de República mais ancorado nas tradições latina e ibérica. Há que se considerar, portanto, com alguma atenção, o fato de que a Inconfidência Mineira se deu num contexto de transição e que o movimento era fortemente marcado pela defesa de privilégios estamentais anteriormente obtidos e tidos como objeto de recuperação por vários dos protagonistas. Celso Lafer, em artigo publicado por ocasião do centenário da Republica no Brasil lembra, oportunamente, que na maior parte das línguas germânicas o termo República esteve associado à idéia de comunidade (commonwealth). Nas línguas neolatinas, por outro lado, sobretudo a partir de Nicolau Maquiavel, foi com freqüência associada a idéias de situação e status, evoluindo posteriormente para o próprio conceito de Estado ${ }^{19}$.

Tomemos aqui algumas evidências que corroboram nosso argumento. Exis- 
tem inúmeras referências no Recueil que aludem à observância de alguns dos princípios esboçados por Locke em seu "Segundo tratado sobre o governo civil”, como, por exemplo, no que respeita ao problema da igualdade relativa, objeto privilegiado por nosso exame. Este é o caso da proposta de vetar, para que não se consolidassem posições de poder privilegiadas, o acesso ao sistema de representação parlamentar daqueles que recebessem qualquer tipo de renda do Estado. Igual raciocínio se aplica à proibição, imposta a todos os Estados, de manter tropas e milícias em tempo de paz. A igualdade relativa também é o pressuposto da proibição, imposta ao Estado, de conceder qualquer tipo de título nobiliárquico e, ainda, da afirmação de que o Estado deve garantir, como condição de liberdade, o livre acesso à propriedade, inclusive a territorial através de doação pública ${ }^{20}$. Para cada um destes temas existem evidências, no que se refere às decisões e tendências dos inconfidentes de 1788-89, de que o sentido geral do projeto por eles esboçado era frontalmente contrário aos princípios contidos no Recueil. Tal constatação parece demonstrar que, se por um lado os inconfidentes pareciam ter como horizonte da República uma região restrita, o que os aproximava da visão de Montesquieu, por outro lado, quanto ao formato da República pretendida, o grupo muito pouco avançou. Os inconfidentes pareceram, ao mesmo tempo, se distanciar do modelo que se delineava na América, o modelo da democracia representativa, e negar, naquilo que diz respeito à participação ampla, o modelo da democracia direta.

Quanto ao primeiro subitem, acerca do acesso de detentores de renda do Estado ao sistema de representação, lembremos o fato de que homens como Gonzaga, Cláudio, Alvarenga e Vieira, tidos como os legisladores e lideranças intelectuais do levante, tinham (ou tiveram) ligação visceral com o Estado português até, pelo menos, início da década de oitenta do século XVIII. Cláudio Manoel da Costa fora nomeado para diversos cargos públicos, só abandonando a carreira burocrática em 1773. Alvarenga Peixoto sempre ocupara postos públicos remunerados seguramente até a gestão de d. Rodrigo José de Meneses (1780-1783). Tomás Antônio Gonzaga, sempre citado como, dentre todos, o maior legislador e inquestionável liderança, estava nomeado para cargo público na Bahia e dependia inexoravelmente das rendas do Estado para sobreviver. Seu patrimônio pessoal se assemelhava, quali-quantitativamente, ao do guarda-livros de João Rodrigues de Macedo, ou ao de oficial de média patente Tiradentes. Não possuía escravos ou qualquer outro bem que lhe pudesse atribuir renda, o que inviabilizaria sua sobrevivência política apenas a partir do dispêndio de seu patrimônio. É pouco provável que fosse aderir às teses do Recueil. É pouco provável que abrisse mão tanto de sua ascendência sobre a nova República quanto de eventual renda que dela partisse.

Quanto ao segundo subitem, relativo à desmilitarização em tempos de paz, 
mencione-se o fato de que alguns dos principais argumentos de convencimento utilizados por Tiradentes e José Alvares Maciel entre os conjurados eram ligados às instruções de Martinho de Melo e Castro (janeiro de 1788), as quais, tratando da dissolução dos regimentos auxiliares e reorganização das tropas regulares, feririam poderosos interesses na Capitania. As instruções teriam sido motivo de grande inquietação e extrema irritação em muitos que, como Joaquim Silvério e Alvarenga Peixoto, haviam comprado patentes à época de Luís da Cunha Meneses e agora podiam perdê-las sem nenhuma contrapartida. Além da possível adesão de Joaquim Silvério e Domingos de Abreu Vieira, o tema mobilizou alguns outros, como o próprio Paula Freire de Andrade, comandante da tropa regular ${ }^{21}$.

Quanto ao terceiro subitem citado, relativo à negação de qualquer título nobiliárquico por parte do Estado, é conveniente lembrar, além das veleidades aristocráticas do casal Alvarenga, do empenho com que Cláudio se batera para obter o "Hábito de Cristo" e os versos e tafularias de Critilo, a própria monografia sobre o Direito Natural, de Tomás Antônio Gonzaga. Do ponto de vista legislativo, seu único texto conhecido é o Tratado de Direito Natural, dedicado ao marquês de Pombal, em que tece profundas críticas a algumas das teses do sistema "democrático-representativo" e pende pela defesa da monarquia, desde que não 354 degenerada pelo despotismo. Tomás Antônio Gonzaga procura estar alerta, parece ser um arguto leitor de seu tempo e de uma nova ordem, mas não um revolucionário. Não parece, assim como muitos dos seus "parciais”, querer avançar na ruptura da ordem social e romper com os privilégios assegurados aos homens bons do mundo luso-brasileiro. Os inconfidentes queriam de fato "reformar" as relações metrópole-colônia, e disto há sobejas evidências. Por outro lado, não pareciam muito preocupados com a instituição de um sistema minimamente representativo.

0 argumento mais decisivo em favor desta hipótese está, ainda uma vez, nos próprios ADIM. Vejamos o quarto subitem destacado em relação ao Recueil, a questão da propriedade. É o editor, Regnier, quem reproduz uma nota, de "um americano", que nos dá a real dimensão da enorme distância entre os inconfidentes de Minas e os americanos do norte:

Talvez cause surpresa encontrar a distinção de "homens livres" num país no qual se crê que todos os homens o sejam. Existe ainda na América duas classes que não o são: uma inteiramente escrava, a dos negros. Na verdade, diversas colônias (e mesmo a maior parte) se têm sempre oposto à importação de escravos, e muitas fizeram leis para impedi-la; mas como a confirmação da coroa era necessária para confirmar, estas leis jamais puderam ser postas em vigor, pois o rei sempre as rejeitou como contrárias aos interesses da Companhia Inglesa na África. (...) De- 
vemos crer que não tardará a abolição da escravatura em toda a área das treze colônias, pois alguns proprietários da Pensilvânia, por seu próprio gosto, deram liberdade aos seus. ${ }^{22}$

Não obstante a "boa vontade" manifesta por nosso comentador, seria preciso mencionar que suas expectativas quanto à abolição da escravatura levariam ainda algumas décadas para se concretizarem, o que se daria apenas na segunda metade no século XIX e, ainda assim, mediante cruenta guerra civil. 0 fato de enunciar o tema como um problema e afirmar certa disposição em resolvêlo, no entanto, já são indícios de relativa distância em relação aos inconfidentes de Minas. Logo adiante, o mesmo comentador alude de maneira ainda mais expressiva e reveladora à outra classe de "homens não-livres":

A outra classe de "homens não-livres" não sofre escravidão, mas é privada de liberdade no sentido político desta palavra, que implica participação no governo e o direito de voto nas eleições dos oficiais públicos. Esta segunda classe se subdivide em várias espécies. 1) as crianças menores de 20 anos (...) 2) os aprendizes de ofícios (...) 3) os empregados domésticos. ${ }^{23}$

No caso desta última classe de "não-livres" é preciso anotar que, consoante à inspiração lockeana do documento, eles são considerados como não-livres não exatamente por serem pobres mas, especificamente, por estarem privados da condição de propriedade, suposto fundante da vida social e do exercício da liberdade civil. Quando se refere aos empregados domésticos, o comentador alude a que, havendo muitos estrangeiros pobres que, tendo pretendido emigrar para a América, contraíram dívidas que os colocaram em situação de sujeição pessoal "por prazo determinado". Não deveriam, nesse sentido, possuir os ditos direitos políticos enquanto persistisse a ascendência de seus patrões sobre eles. 0 mesmo se aplicava aos aprendizes em relação aos mestres e às crianças em relação aos pais.

0 problema que nosso comentador anônimo procura levantar, acerca das relações entre indivíduo, condição econômica e representação política, seria um problema central na Europa e na América nos anos que se seguiriam, e diz respeito exatamente à definição das bases de organização do sistema representativo no sentido moderno, um dos primeiros indícios da emergente noção de cidadania que, como sabemos, era noção desconhecida nas sociedades do Antigo Regime $^{24}$. Se na revolução americana já podemos perceber que o tema pontificava na cabeça dos revolucionários, bem diverso era o caso nas Minas.

No que se refere a estas pequenas citações e, por que não dizer, ao documento como um todo, o que nos salta aos olhos é o relativo descompasso entre as premissas nela contidas e os temas centrais dos debates que eram empreen- 
didos nas Minas setecentistas. Não há, nos ADIM, uma única menção a que os inconfidentes houvessem discutido o tema da representação política e do compromisso com a liberdade individual nesses termos. Um dos temas mais candentes na organização do novo Estado, o problema da representação política, foi com freqüência associado ao sistema representado pelas câmaras, locais de reunião e expressão apenas dos homens bons. Quanto ao tema da liberdade, era referido exclusivamente às relações entre Portugal e sua colônia na América e, quando muito, à crítica da atuação de seus ministros e representantes. A afirmação da liberdade política como princípio fundante da própria vida social parecia relativamente desconhecida de nossos protagonistas e, no entanto, foi diversas vezes a eles associada pela historiografia de referência da Inconfidência Mineira.

0 tratamento da questão da propriedade, mesmo no sentido apenas material, também se deu nos limites do Antigo Regime. Líderes expressivos e intelectuais reconhecidos como José Alvares Maciel e José Resende Costa Filho viviam, ainda depois dos trinta anos, sob "pátrio poder" e não possuíam bens que fossem objeto de seqüestro. Não pareciam incomodados com a questão da "propriedade" e tampouco, numa sociedade em que exercer os chamados "ofícios mecânicos" ou atividades de comércio eram considerados ultrajantes, pareciam cultivar a noção da "propriedade" sobre sua capacidade de trabalho como valor ético fundante de uma nova ordem ${ }^{25}$. Curioso, nesse sentido, é o fato de que José Alvares Maciel foi, segundo a tradição e a historiografia de referência, aquele que teria trazido um dos exemplares do Recueil para o Brasil e, logo em seguida, teria com ele presenteado o alferes Joaquim José da Silva Xavier. Na reunião decisiva de 26 de dezembro de 1788 , a última a reunir os principais líderes do levante, na qual se deliberou pela manutenção do trabalho escravo, tanto um como outro, presenteador e presenteado, corroboraram aquela decisão, tendo Maciel, inclusive, usado do argumento mais decisivo.

Não nos esqueçamos de que o tema da escravidão já era condenado em Voltaire, presente nas livrarias do cônego Vieira, Cláudio Manoel da Costa, Alvarenga Peixoto, José de Resende Costa e do padre Manoel Rodrigues da Costa. 0 tema seria condenado também em Montesquieu, do qual os inconfidentes beberam, mesmo que indiretamente, apenas o conceito geograficamente restrito de República. Nosso "comentador anônimo", em que pesem os limites estruturais que fatalmente se colocariam em contraponto às suas expectativas, bem como ressalvados os componentes ideológicos contidos no texto, parece a todo tempo se reportar ao futuro, à utopia de uma nova ordem. Não é apenas ele: a condição de "homem livre" era, no Recueil, colocada como condição a ser ampliada e estendida, na medida da evolução histórica, a cada vez maior número de pessoas. 
Nossos inconfidentes, por seu turno, reafirmaram em vários momentos seus compromissos com a recuperação do passado, desde que liberto das amarras coloniais ou neo-mercantilistas. Entre o conceito de homens livres, fundamento da nova ordem, e o de homens bons, típico do Antigo Regime português estabelecido nas Minas, nossos protagonistas estiveram, como de resto em relação a vários outros temas, bastante divididos, quando não penderam para o passado. Tiradentes, segundo é corrente na historiografia, não só possuía um volume do Recueil, como o lia obsessivamente e pedia que lhe traduzissem partes. É, dentre todos os inconfidentes de Minas, excetuando-se talvez o cônego Vieira, o que mais parecia ter uma real percepção da dimensão dos acontecimentos na América inglesa e suas possíveis repercussões para a História. Por outro lado, seu patrimônio apresenta tipologia e número de peças de vestuário e toucador bastante próximo ao aristocrata Tomás Antônio Gonzaga, o que não é, no século XVIII, questão desprezível. Ao ouvidor Gonzaga, homem da corte, o alferes pode ser comparado em virtude do apreço à indumentária, fator de distinção (desigualdade) no qual se funda toda a política setecentista. Tiradentes era, ainda, um miliciano em "tempo de paz" e lutava pela manutenção dos corpos de ordenanças auxiliares. Votou pela escravidão criticada no Recueil, ou consentiu por omissão. Finalmente, sobre o levante, dizia com paixão: "não diga levantar... é restaurar"26.

Por outro lado, alguns inconfidentes propuseram que todos pudessem usar cetins, o que poderia prenunciar a busca de maior igualdade entre os homens e a ruptura com certos padrões do Antigo Regime. Os próprios termos em que o argumento é vazado, contudo, espelham o fato de que, na América portuguesa, ainda haveria um longo percurso a ser trilhado e muitas mediações a serem feitas. É o padre Toledo quem nos sugere esta interpretação. Teria apresentado, em depoimento a 27 de novembro de 1789 , como proposta do levante, a idéia de que os nobres, ainda ascendendo sobre "os povos" ou "as gentes", deveriam ser um exemplo para os de "inferior qualidade". Relata o padre que "os nobres não haviam de vestir senão das fazendas próprias do País, e que os de inferior qualidade vestiriam das que quisessem, e deixava-se-lhes essa liberdade na esperança de que estes seguiriam o exemplo daqueles". ${ }^{27}$

Os dados apresentados são expressão de uma situação e época de transição. Em 1788-89, a ordem liberal ainda em construção; apenas se prefigurava nos continentes europeu e americano. Em ritmos e sob formatos e roupagens diferentes, "ganhava" diferentes regiões e adeptos. Se foram identificadas, entre os inconfidentes, tantas evidências do exemplo norte-americano no que tange à demonstração da exeqüibilidade de uma independência das Minas, diríamos, por outro lado, que o referencial político a ser adotado nas Minas não era predominantemente o que se consagraria entre os americanos do norte. Quanto à 
forma de governo, a maior parte dos inconfidentes, em especial Tomás Antônio Gonzaga, parecia comungar muito mais com a concepção da monarquia nãodespótica, tal com formulada em Montesquieu ou na segunda escolástica do padre Vieira, do que com a República representativa dos "americanos ingleses" Adams e Hamilton. Sobre Tomás Antônio Gonzaga, afirma Luís Carlos Villalta:

Examinando-se atentamente as imagens do bom governo e da tirania constituídas pelo poeta de Vila Rica, fica evidente a sua filiação à segunda escolástica e, ainda, sua proximidade com as críticas feitas por Antônio Vieira, também elas escolásticas. 0 governante não pode tudo; deve respeitar as leis, as diferenças de direito e as hierarquias havidas no interior dessa sociedade, a capacidade dos povos de pagar os tributos; necessita procurar a felicidade do Reino, repartir com justiça prêmios e castigos. Inversamente, é tirano o governante que age de forma oposta a esses princípios. ${ }^{28}$

Não obstante tivesse procurado dar corpo a um teoria para a forma republicana e estabelecer algumas de suas virtudes, Montesquieu acabaria, no século XVIII, ainda tomando partido pelo maior grau de excelência da monarquia. 0 que essas asserções sugerem é o fato de que, para além do contraponto entre Monarquia e República, o que se deve considerar na análise da Inconfidência Mineira é, sobretudo, o contraponto despotismo/tirania x governo justo tal como na concepção construída por Cícero. Não era de soberania do povo e vontade geral, no sentido liberal contemporâneo, que falavam os inconfidentes de Minas. Falavam com mais freqüência de interesses individuais e identidades estamentais. Pelo que foi exposto, nos parece que é de homens como Gonzaga que a teoria da excelência da monarquia de Montesquieu "fala". Muitas de suas iniciativas e intervenções parecem demonstrar que nosso poeta, sem dúvida um dos mais informados dos inconfidentes, está se propondo a cumprir, através de sua "câmara reformada", como tentou ainda em 1789, o papel de anteparo ao despotismo real. Mais uma vez lembremos de sua literatura. Escreve Gonzaga logo na abertura de suas Cartas Chilenas, "dedicadas aos grandes de Portugal":

Um Dom Quixote pode desterrar do Mundo as loucuras dos Cavaleiros Andantes: um fanfarrão Minésio pode também corrigir a desordem de um governador despótico. Lê, diverte-te, e não queiras fazer juízos temerários sobre a pessoa do Fanfarrão. Há muitos fanfarrões no mundo, e talvez que tu sejas também um deles,...Quid rides? mutato nomine, de te Fabula narratur.....

Destacando o caráter exemplar e educativo de seus versos, o autor se inscreve plenamente na concepção reformista do Iluminismo ${ }^{30}$. A defesa de Gonzaga ante a alçada, brilhante como peça jurídica, é também reveladora de suas con- 
cepções sobre ação social, poder e Estado: ao enunciar os motivos pelos quais não poderia (e não pretenderia) ter se envolvido na Inconfidência, ele constrói sua argumentação num crescendo, do mais privado ao mais público, que culmina com a reafirmação da aceitação da legitimidade da Casa Real que a princípio parecera combater. Acompanhemos seu depoimento:

Que antes pelo contrário há muitos indícios que mostram que o réu respondente não pode ser entrado em semelhante conjuração como são os seguintes que aponta: Primeiro o de ser filho de Portugal, onde tem bens, e pai no graduado lugar de Desembargador de Agravos: Segundo o estar despachado para o lugar de Desembargador da Bahia, e não ser de presumir, que quisesse perder esse emprego útil e certo, por coisa incerta e menos útil que se lhe pudesse oferecer: Terceiro porque estando justo a casar, não se havia de querer expor a uma guerra civil, e contra os parentes de sua esposa, que são todos militares: Quarto, que os mesmos da terra o não haviam de querer convidar, por ser filho do Reino, não ter bens nenhuns, nem préstimo militar com o que os pudesse ajudar, e não se haverem de sujeitar a expor suas pessoas, e bens para adquirirem empregos, que dessem ao réu respondente, que não se contentaria senão com os maiores: Quinto, porque logo que chegou a monção para a Bahia, pediu o réu respondente ao Exmo. General da Capitania que no caso de não vir (do Reino) sua licença para casar, lha havia (o próprio General) de conceder (...) Sexto: porque tendo chegado ordem de Sua Majestade para se lançar a derrama, ele réu respondente disse ao intendente de Vila Rica, Procurador da Coroa, que o tributo era grande, e que temia alguma revolução no povo (...) e Sétimo, porque ele réu, sempre que falou com o Exmo. General lhe disse que nem se podiam cobrar as dívidas da Coroa por serem muitas, e estar o povo muito pobre, e que se deveria representar a Sua Majestade o estado da Capitania, para as perdoar, o que não faz quem quer ser rebelde, que procura a vexação do povo. ${ }^{31}$

Os inconfidentes de 1788-89 em Minas não tinham, na sua maioria, absoluta clareza da distinção entre o bem público e o interesse privado. Estas instâncias se misturam, naturalmente, em suas práticas discursivas e políticas. Gonzaga, na África (junto a muitos outros) continuou a serviço da Coroa com o mesmo brilho e diligência que já havia demonstrado anteriormente. A distinção por ele operada entre aparência e essência (potência e ato) no mesmo depoimento não é simplesmente um artifício jurídico no sentido moderno: é um pensamento historicamente construído e que precisa ser historicamente explicado. Não é, por motivos óbvios, sua negativa de envolvimento que mais nos interessa. Seria surpreendente se admitisse sua culpa. O que mais nos interessa é a forma do argumento, que pode trair significados profundamente reveladores e não explicitados pelo autor. Ele parece dialogar (contraditando) com vários pontos 
do Recueil. Em sua defesa estão presentes a questão da propriedade e sua falta, da igualdade e da diferença enquanto fundadores da ação política, da necessidade da imposição de limites ao poder real. 0 mais importante, todavia, é que ela nos permite recuperar alguns aspectos dos móveis de ação que inspiraram os rebeldes de 1789. Partindo da exposição dos motivos, dos mais íntimos e privados aos mais públicos, o autor da fala revela, junto à sua poesia, à tipologia de seus bens, às suas articulações políticas, que não se pretendia ir muito longe no levante. Quando muito se chegaria a uma recuperação de privilégios. Seus argumentos demonstram que não existe apenas a grande "Inconfidência", inscrita no campo geral da contestação iluminista revolucionária do Estado Absolutista. Há aspectos endógenos, interiores ao mundo luso-brasileiro e, ainda, contradições e ambições próprias dos protagonistas.

De todo o exposto, fica a sugestão de que, dentre o repertório político disponível, os inconfidentes teriam feito heterodoxa leitura. De Raynal e dos "americanos ingleses" beberam a ideologia e práticas anticoloniais. De Montesquieu, provavelmente beberam algumas teses selecionadas. Se, por um lado, trabalharam no horizonte de uma república, ainda que de reduzidas dimensões, por outro, pouco avançaram na discussão do tema da participação política ou da tripartição de poderes, elementos fundantes da república representativa e uma das maiores contribuições de Montesquieu ao pensamento político. Do ponto de vista jurídico, outro dos aspectos mencionados por nosso autor, não se conhecem evidências de que os inconfidentes procurassem tratar o tema em perspectiva que nem sequer introduzisse o tema da cidadania ou da igualdade jurídica nas acepções contemporâneas.

Em último lugar, se Montesquieu, acerca das diferentes forças de integração social que articulam as formas de governo, nos afirma que "na República é a virtude que leva os cidadãos a antepor o bem do Estado ao interesse particular; e na monarquia é o senso de honra da nobreza que é sustentáculo, e ao mesmo tempo limite do poder do rei”, ${ }^{32}$ diríamos que na Inconfidência de 1789 há um permanente jogo de trocas entre virtude e honra, que entendido no contexto setecentista mineiro, dificilmente separa com clareza interesses públicos e virtudes privadas, ou vice-versa. Em suma, do ponto de vista estritamente espacial, o levante se circunscrevia à Capitania de Minas Gerais e não se referia, portanto, à emancipação política do país ou a um projeto de nação em sentido contemporâneo. 0 apelo republicano, por seu turno, esteve estreitamente associado a uma definição relativamente circunscrita no seu tempo e que, por sua vez, representa um momento de transição no pensamento político ocidental. Quanto à natureza do levante em relação ao grau de ruptura ou radicalismo que se pretendia, ou seja, se era um movimento "reformista", "revolucionário" ou, ainda, 
mais um episódio de conflito e negociação entre a Coroa e seus súditos de alémmar, é um tema que precisa ser melhor investigado pela historiografia.

\section{NOTAS}

${ }^{1}$ Cf. MATTEUCCI, Nicola. República. In Dicionário de Política. Brasília: UNB, 1986, p. 1.108.

${ }^{2}$ Os quais estão notavelmente delineados no Recueil des loix constitutives des colonies angloises, confédéerées sous la dénomination d'États Unis de l'Amérique Septentrionale, documento que fazia parte das discussões de alguns dos inconfidentes, segundo várias menções nos Autos de Devassa da Inconfidência Mineira. Para o apontamento dos possíveis possuidores do texto, ver: Autos de Devassa da Inconfidência Mineira (ADIM), v.3, pp.20-23.

${ }^{3}$ Para uma descrição detalhada das diversas correntes do Iluminismo e sua recepção no mundo luso-brasileiro, ver: VILLALTA, Luís C. Reformismo Ilustrado, Censura e Práticas de Leitura: Usos do Livro na América Portuguesa. São Paulo: FFLCH/USP, 1999. 546 p. (Tese de Doutoramento) (em especial, páginas 95-134).

${ }^{4}$ Voltaire e Diderot, como se sabe, eram mais publicistas e agitadores que "formuladores teóricos" propriamente ditos. Junto com Montesquieu estão, entre outros, presentes nas livrarias setecentistas mineiras. Os sequestros que detalharam os livros apreendidos são os de Cláudio Manoel da Costa, Alvarenga Peixoto, José de Resende Costa, cônego Vieira e Manoel Rodrigues da Costa.

${ }^{5}$ Cf. MATTEUCCI, Nicola. Op. cit. p. 1.108.

${ }^{6}$ Idem.

${ }^{7}$ Cf. JARDIM, Márcio. Inconfidência Mineira: uma sintese factual. (1ª ed., 1988). Rio de Janeiro: Biblioteca do Exército, 1989; SANTOS, Lúcio José. A Inconfidência Mineira: Papel de Tiradentes na Inconfidência Mineira. (1 ${ }^{\underline{a}}$ ed., 1927). Belo Horizonte: Imprensa Oficial, 1972.

${ }^{8}$ Cf. SOUSA E SILVA, Joaquim N. Historia da Conjuração Mineira. (1 ${ }^{a}$ ed., 1873). Rio de Janeiro: Imprensa Nacional, 1948. 2v. p 72.

${ }^{9}$ Cf. MAXWELL, Kenneth. A Devassa da Devassa: A Inconfidência Mineira, Brasil - Portugal, 17501808. (1ª ed., 1973). Rio de Janeiro: Paz e Terra, 1985, p. 151.

${ }^{10}$ Cf. JARDIM, Márcio. Op. cit., p. 344.

${ }^{11}$ Idem, p. 354.

${ }^{12} \mathrm{Cf}$. RUSSEL-WOOD. A. J. R. Centro e periferia no mundo luso-brasileiro. In Revista Brasileira de História, v.18, n.36, pp.187-249; ADIM, v.1, p.351.

${ }^{13}$ Cf, ADIM, v.1, p.258.

${ }^{14}$ Depoimento em 15 de junho de 1789. Cf. ADIM, v.2, p.49.

${ }^{15} \mathrm{~A}$ respeito da importância das câmaras no contexto setecentista mineiro e na Inconfidência de 1789, ver FURTADO, João P. Inconfidência Mineira; crítica histórica e diálogo com a historiografia. São Paulo: FFLCH/USP, 2000. 340 p. (Tese de Doutoramento).

${ }^{16} \mathrm{O}$ visconde de Barbacena, nesse sentido, situar-se-ia talvez naquela linhagem de governadores, 
na qual se incluem Gomes Freire de Andrade e d. Rodrigo José de Meneses, aos quais Laura de Mello e Souza atribui a estratégia de conciliar o agro e o doce no sentido de obter a submissão dos povos. A respeito, ver: SOUZA, Laura de Mello e. Norma e Conflito; aspectos da História Mineira no século XVIII. Belo Horizonte: UFMG, 1999.

${ }^{17}$ Um resumo sobre os planos pode ser encontrado em Márcio Jardim. Cf. JARDIM, Márcio. Op. cit., pp. 350-353.

${ }^{18}$ Cf: MAXWELL, Kenneth. op. cit., p.151; SOUZA E SILVA, Joaquim N. Op. cit., pp. 43-45, 81; JARDIM, Márcio. Op. cit., pp. 346-347; SANTOS, Lúcio J. Op. cit., p. 99.

${ }^{19}$ Cf. LAFER, Celso. 0 significado de República. In Estudos Históricos, Rio de Janeiro, vol. 2, nº 4, 1989, pp. 214-224.

${ }^{20}$ Cf. ADIM, v.3, p.45; ADIM, v.3, pp.35, 41, 44, 71, 106; ADIM, v.3, pp.40 e 114.; ADIM, v.3: pp.66, 68,71 .

${ }^{21}$ A respeito, ver: MAXWELL, Kenneth. Op. cit., p. 146.

${ }^{22}$ Cf. ADIM, v.3, p.65.

${ }^{23}$ Idem.

${ }^{24} \mathrm{~A}$ cidadania plena, na sociedade burguesa, teria como premissa a coerente articulação entre Estado (instância normativa) e direitos políticos, civis e sociais. Sobre a construção do conceito de cidadania em perspectiva histórica, ver: MARSHALL, T. H. Citzenship and Social Class. London: Cambridge U. P., 1950.

${ }^{25}$ Cláudio Manoel da Costa, quando postulou o "Hábito de Cristo", teria sido obrigado a despender não poucos cruzados para "esconder" que um avô paterno comerciara azeite, o que o desabilitava no pleito. Por outro lado, diz a trigésima sexta seção da Constituição da Pensilvânia: "todo homem livre (pois não existe bem maior) deve ter alguma profissão, mister, comércio, ou propriedade rural que lhe permita viver honestamente". (grifo nosso) Cf: ADIM, v.3, p.93.

${ }^{26}$ Segundo Basílio de Brito Malheiro do Lago, CF. ADIM, v.1, pp.104, 152, 229.

${ }^{27}$ Cf. ADIM, v.5, p.143.

${ }^{28}$ Cf. VILLALTA, Luís Carlos. Op. cit., p. 470.

29 “Por que ris? Mudado o nome, a História fala de ti." (Horácio, Sátiras, Livro 1, versos 69 e 70.$)$ Cf. Nota do editor. In: GONZAGA, Tomás A. Cartas Chilenas. São Paulo: Companhia das Letras, 1995 , p. 36. 
${ }^{30}$ Cf. FURTADO, Joaci P. Uma república de leitores: história e memória na recepção das Cartas Chilenas (1845-1989). São Paulo: FFLCH/USP, 1994, 244 p. (Dissertação de Mestrado).

${ }^{31}$ ADIM, v.5, pp.209-210.

${ }^{32}$ Cf. MATTEUCCI, Nicola. Op. cit., p. 1.108. 